Iranian Journal of Breast Diseases. 2020;13(3):8-19.
Original Article

\section{Effect of Logo Therapy on Anxiety and Depression in Breast Cancer Survivors Receiving Nutrition Counseling}

\author{
Sajadian $\mathbf{A}^{1^{*}}$, Raji Lahiji $\mathbf{M}^{1}$, Zarati $\mathbf{M}^{\mathbf{2}}$, Haghighat $\mathbf{S}^{\mathbf{1}}$, Zahrakar $\mathrm{K}^{\mathbf{3}}$ \\ ${ }^{1}$ Department of Integrative Oncology and Quality of Life, Cancer Quality of Life \\ Research Group, Breast Cancer Research Center, Motamed Cancer Institute, \\ ACECR, Tehran, Iran \\ ${ }^{2}$ Department of Nutrition, Iran University of Medical Sciences, Tehran, Iran \\ ${ }^{3}$ Consulting Department, Kharazmi University, Tehran, Iran
}

Receive: $12 / 4 / 2020$

Accepted: 27/7/2020

*Corresponding Author:

assajadi@yahoo.com

Ethics Approval:

IR.ACECR.IBCRC.REC.1396.17

\begin{abstract}
Introduction: Depression and anxiety are more common in breast cancer patients. Anxiety and depression not only affect breast cancer patients' quality of life, but also affect their lifestyle. The aim of this study was to determine the effect of logotherapy along with nutrition counseling on anxiety and depression in breast cancer survivors.

Methods: In this randomized controlled clinical trial, 90 breast cancer survivors with a depression score above 14 were recruited. The participants were assigned to either a nutritional counceling (control) or a nutritional counseling plus logotherapy group. The control group received nutrition counseling at baseline and at the end of the fourth week of the study, while the intervention group received 8 weeks of logotherapy in addition to nutrition counseling. Both groups completed the Beck Depression Inventory and underwent anthropometric measurements before and after the intervention period. Data were analyzed using SPSS.
\end{abstract}

Results: The mean (SD) age of the participants was 49 (10) years (range, 2868 years). More than $50 \%$ of people in both groups had an education level of up to diploma or higher; most of them were married; and more than $60 \%$ were employed. In the nutrition counseling group, $80 \%$ had stage I and II cancer, $11 \%$ stage III. In the nutrition counseling plus logo therapy, $65 \%$ had stage I and II cancer, and $24 \%$ had stage III cancer. Within-group comparisons revealed significant decreases in anxiety and depression scores in both groups $(\mathrm{P}<0.001)$. Also, the improvement in anxiety and depression was significantly greater in the nutrition counseling plus logo therapy group compared with the nutrition counseling group $(\mathrm{P}<0.001)$.

Conclusion: This study shows that nutritional counseling and psychotherapy together can improve depression in breast cancer survivors. The use of psychotherapeutic interventions from the beginning of treatment not only balances the mind and mental health, but also improves the lifestyle and prevents its complications.

Keywords: Logotherapy, Nutrition Counseling, Depression 


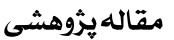

تاثير مشاوره معنادرمانى به همراه مشاوره تغذيه بر اضطراب و افسر دكى در بهبوديافتكان سر طان بـتان

اكرمالسادات سجاديان"'، مهسا راجى لاهيجى'، ميترا زراتى'، شهير حقيقت'، كيانوش زهراكارّ ' ديارتمان كيفيت زندگى و طب فراكير، كروه كيفيت زندگى سرطان، مركز تحقيقات سرطان بِّتان،

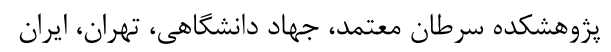

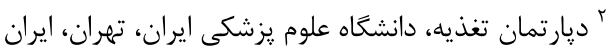

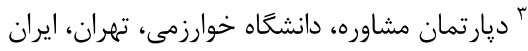

فصلنامه بيمارى هاى بستان ايران

$1 \% 99 ! 1 \%(r): 9-19$

\section{جكيده}

مقدمه: ميزان شيوع افسردىى و اضطراب در مبتلايان به سرطان پِّتان افزايش يافته است. هدف از از

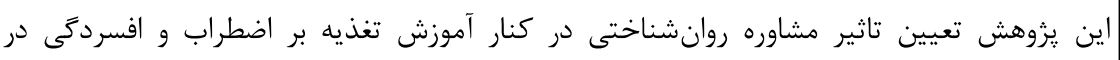

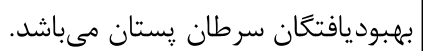

روش بررسى: در اين مطالعه مداخلهاى كه از نوع كارآزمايى بالينى تصادفى شاهددار بوده، •9 نفر از از

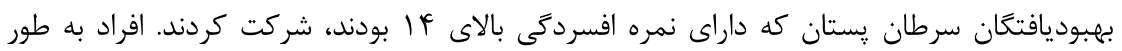

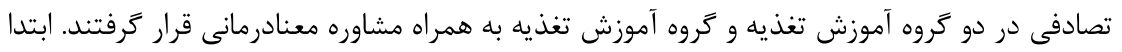

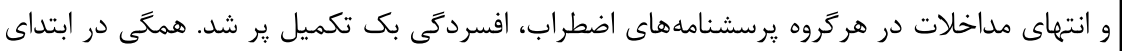

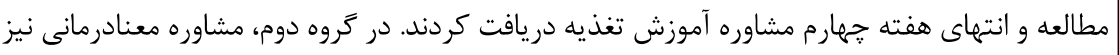

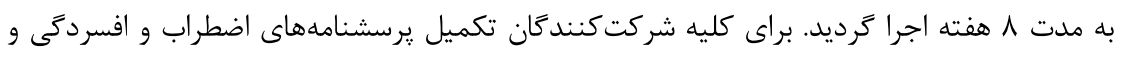

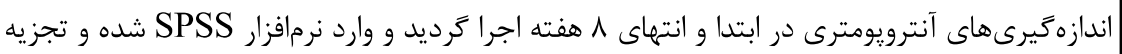

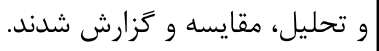

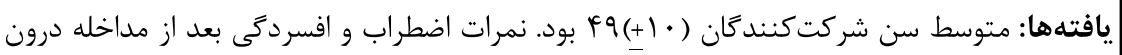

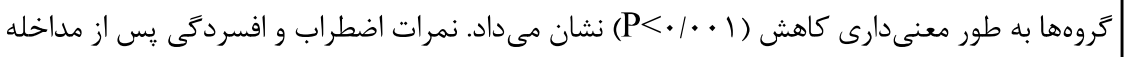

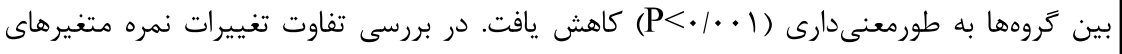

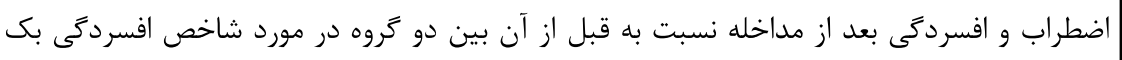

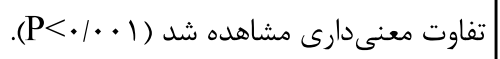
إنتيجدكيرى : نتايج مطالعه حاضر نشان داد كه آموزش تغذيه اصولى و مشاوره معنى درمانى به همراه

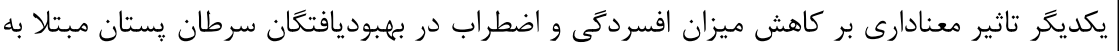

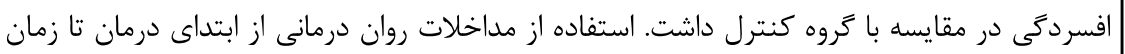

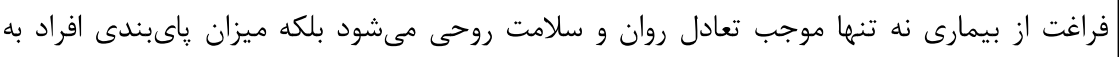

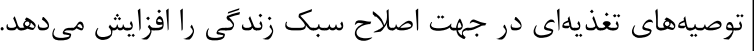
|وازههاى كليدى: معنادرمانى، آموزش تغذيه، افسردىى، سرطان يستان، ايران
تاريخ ارسال: : ت : ت

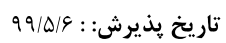

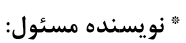
assajadi@yahoo.com 
شد. نتايج اين مطالعه نشان داد، معنادرمانى به شيوه گروهى

باعث كاهش اختلالات از جمله شكايت جسمانى، حساسيت

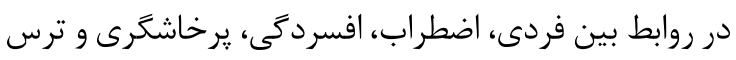

مرضى شد (11). به علاوه يكى ديخر از راه كارهاى كاهش اضطراب و افسردى ).

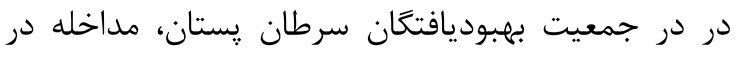

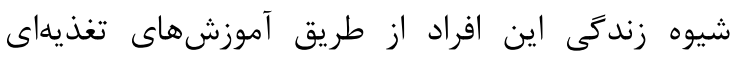

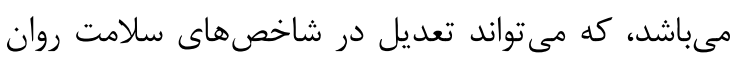

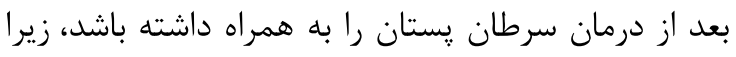

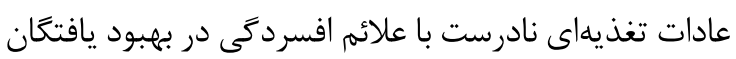
سرطان يستان ارتباط مستقيم دارند (I) (I). مطالعات

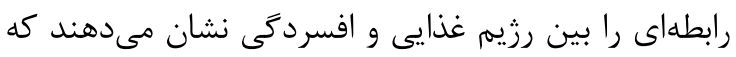

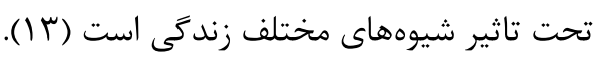

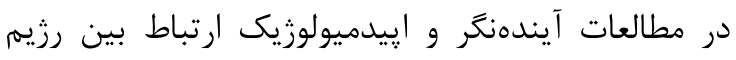

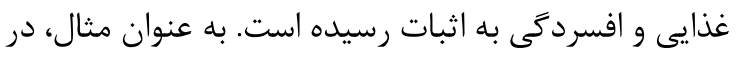

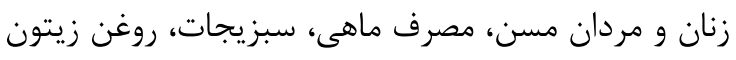

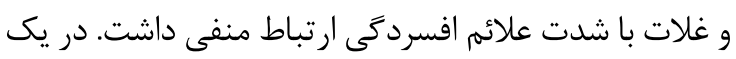

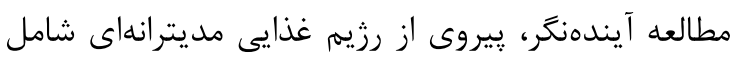

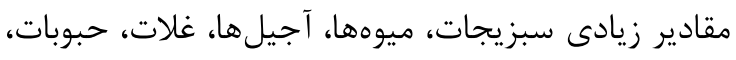

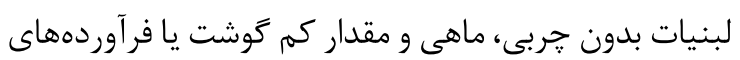

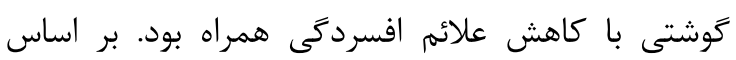

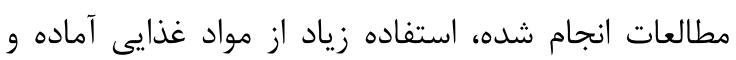

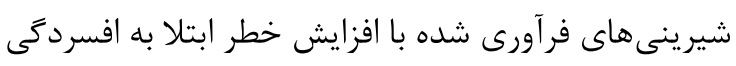

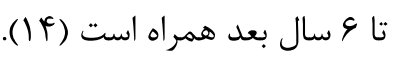

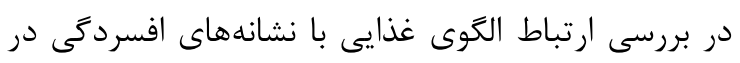

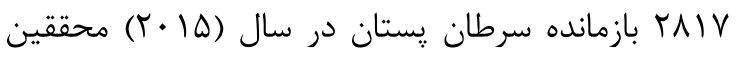

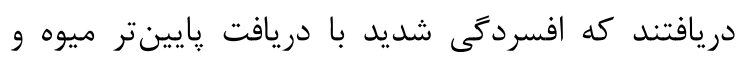

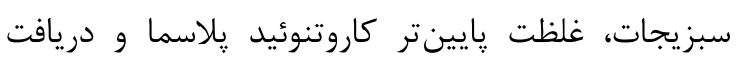

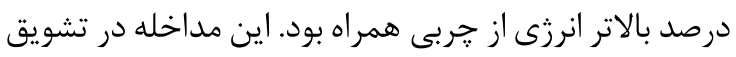

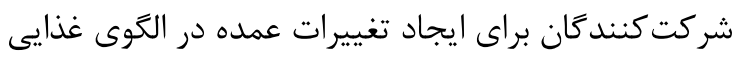

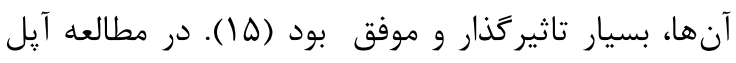

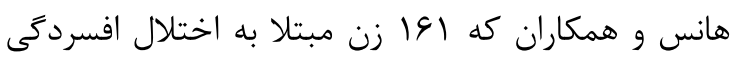

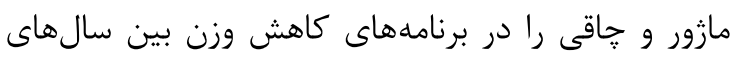

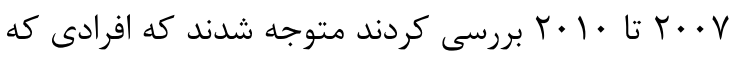

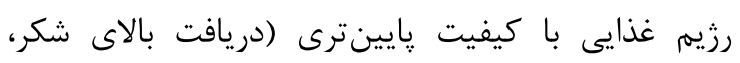

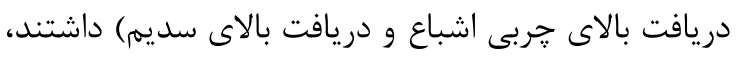

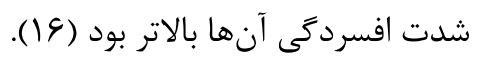

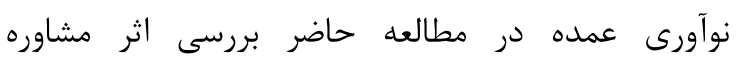

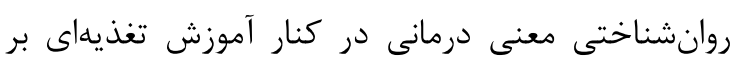

سرطان يستان دومين سرطان شايع جهان و جههارمين علت

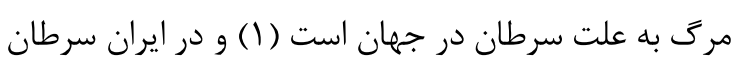

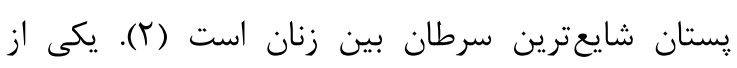

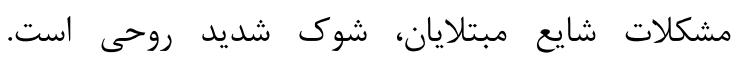

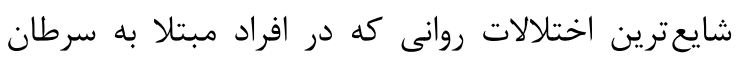

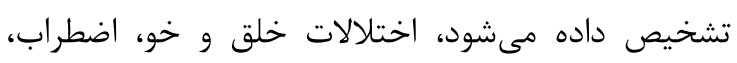

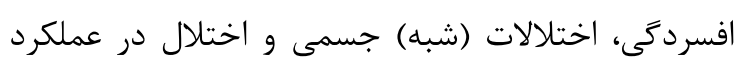

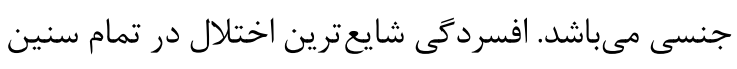

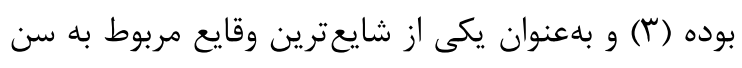

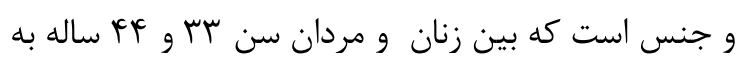

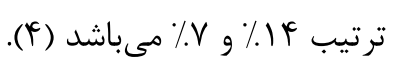

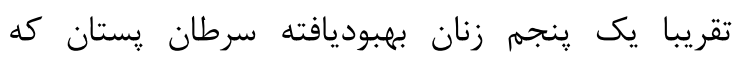

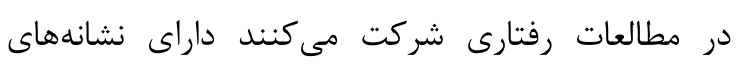

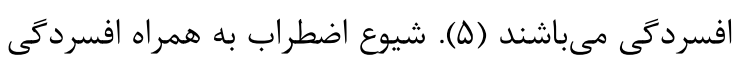

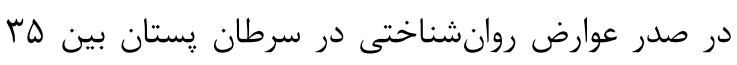

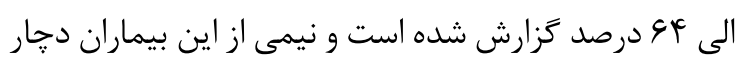

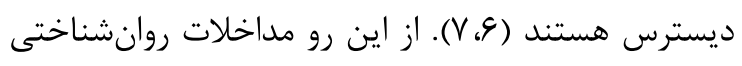
جهت كاهش اضطراب و افسردكى در بيماران مبتلا به

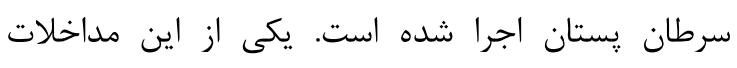

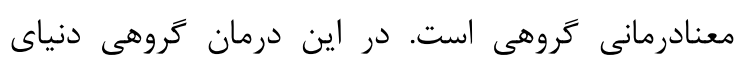

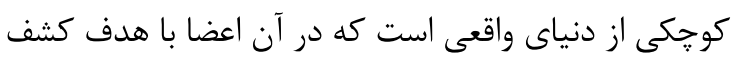

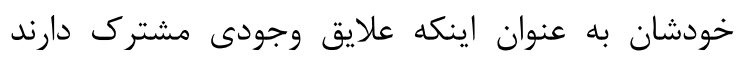

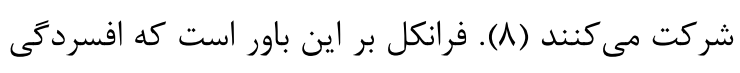

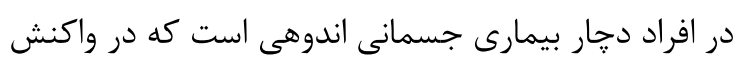

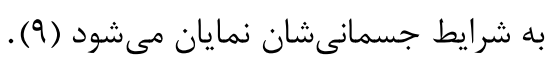

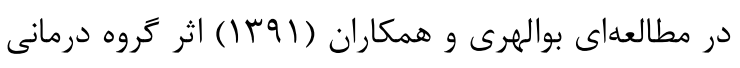

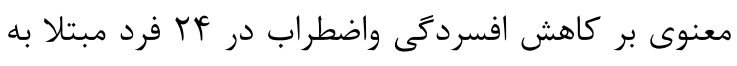

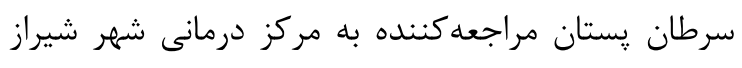

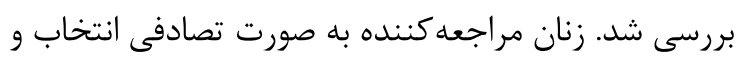

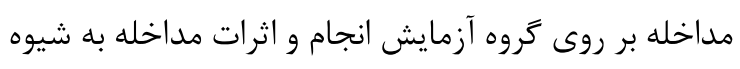

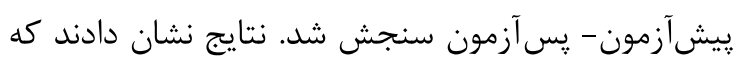

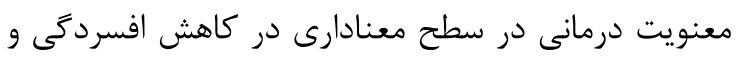

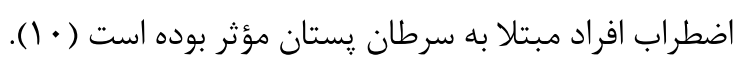

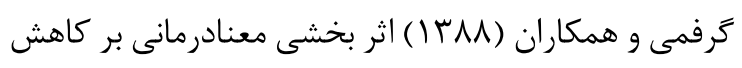

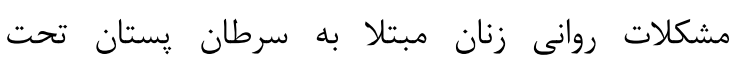

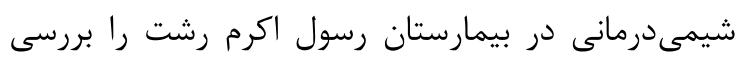

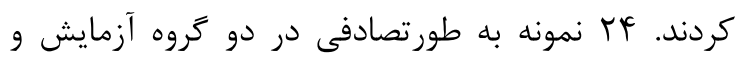
كنترل انتخاب شدند و • ا جلسه مشاوره معنادرمانى انجام 
خودَزارشى تكميل مى

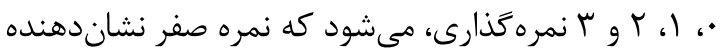

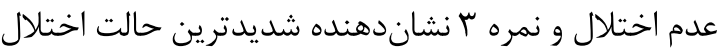

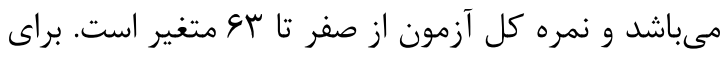
تحليل، نمرات افراد با هم جمع و افرادى كه نمره آنان ·

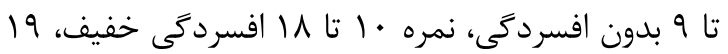

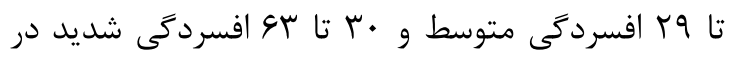

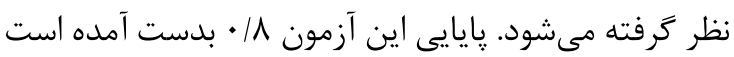

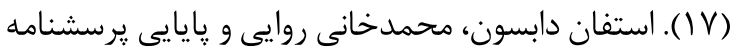

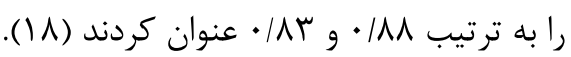

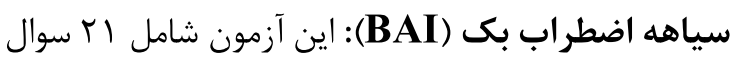
است. طى آن ميزان علائم اضطرابى فرد در يك يك هفته إنه

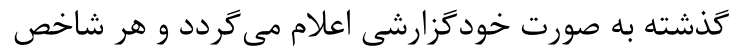
با مقياس جهار درجهاى (• تأ أ) از اصلا تا بسيار شديد نمرهذذارى مىشود بك و همكاران در سال

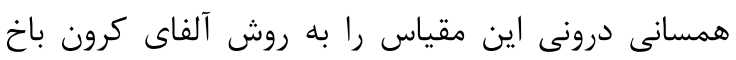

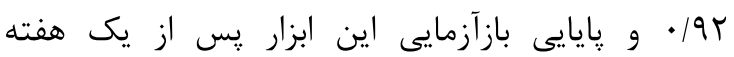

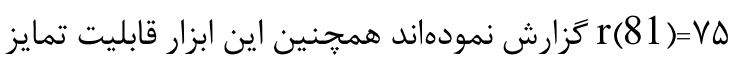

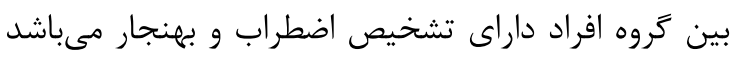
(19). بايايى و روايى نسخه فارسى ابزار نيز توسط كاويانى

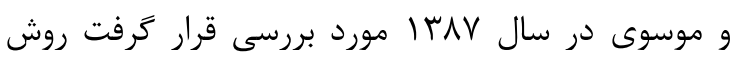

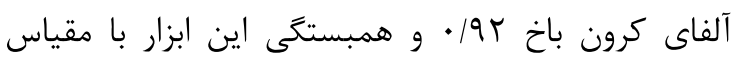

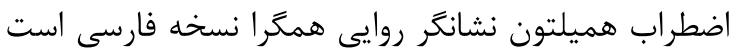

روش اجراى يخوهش: افراد مورد مطالعه از ميان بيمارانى

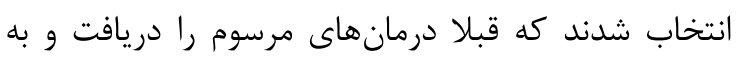
كلينيك ييخيرى سرطان پِتان مركز تحقيقات جهاد دانشخاهى مراجعه كرده بودند. از بين اين افراد، كسانى كه

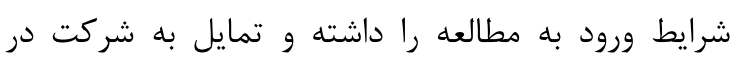
مطالعه را داشتند به صورت تصادفى در كروههاى زير قرار

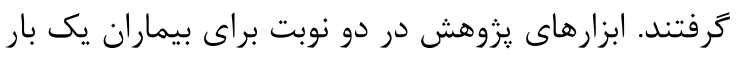

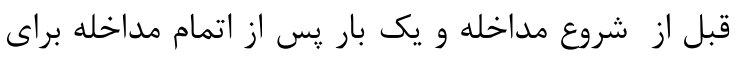

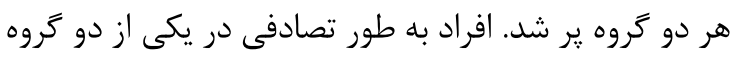

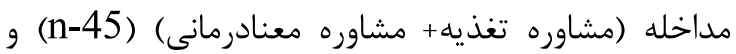

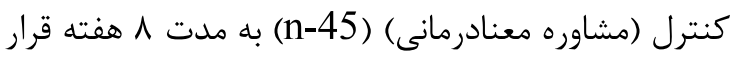

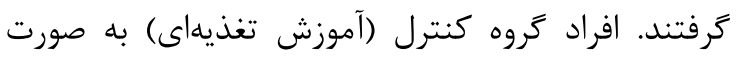
فردى در Y جلسه آموزشى (ابتداى مطالعه و انتهاى هفته جهارم) توسط كارشناس تغذيه تحت مشاوره تغذيه قرار

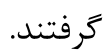

تغييرات ميزان افسردگى و اضطراب در زنان بهبوديافته سرطان يستان مبتلا به افسردكى در مقايسه با گروه كنترل

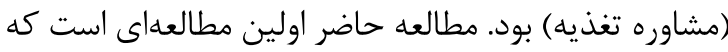
به بررسى اثر مشاوره روانشناختى معنى درمانى

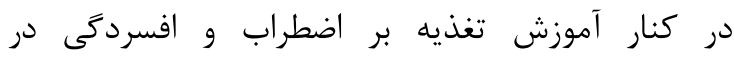

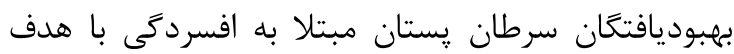

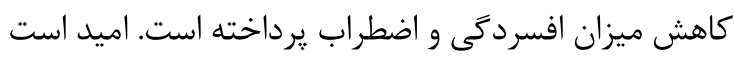

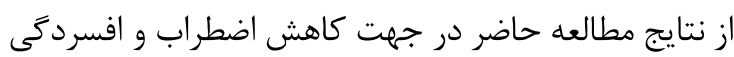
و افزايش كيفيت زندكى در اين بيماران بهره كرفته شود.

\section{مواد و روشها}

اين مطالعه به صورت يك كارآزمايى بالينى تصادفى دو كروهى در جامعه زنان بهبوديافته سرطان يستان مبتلا به به بهان

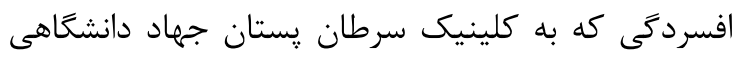

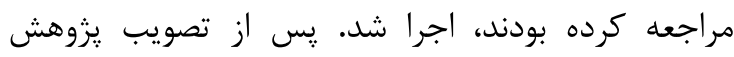

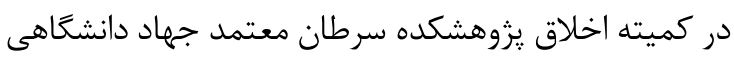

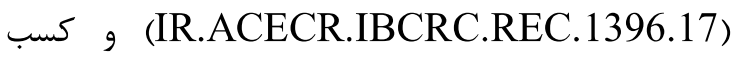
مجوزهاى لازم، انتخاب شركتكنيدكان در يروهش آغاز

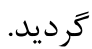
افراد مورد مطالعه از ميان مراجعين به كلينيك يِيخيرى

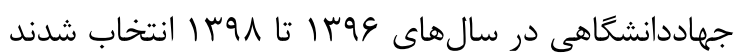

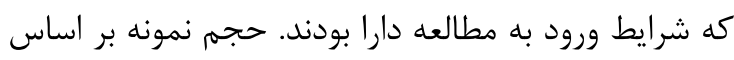

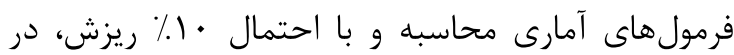

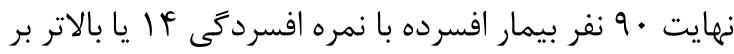

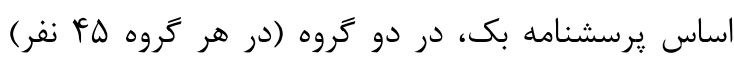
تعيين شد كه در دو مرحله قبل و بعد از در مداخله،

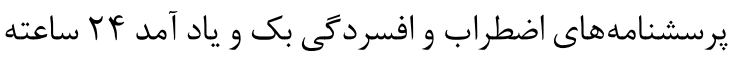
تكميل ترديد. روش نمونه كيرى به طور تصادفى انجام شد.

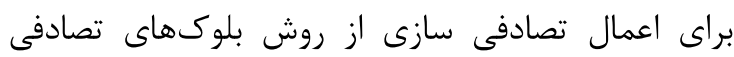
(Permuted Block Randomization)

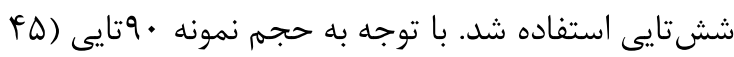

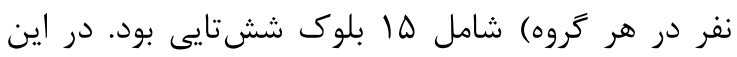

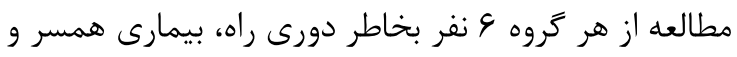
ساير دلايل بيش ازدو جلسه شركت نكرده و اطلاعاتشان از از

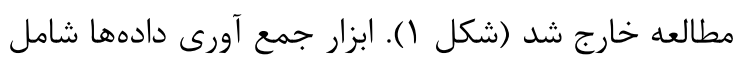
سياهه افسردى بك (BDI) و سياهه اضطراب بك (1) (BAI)

سياهه افسردتى بك (BDI): اين آزمون شامل بود

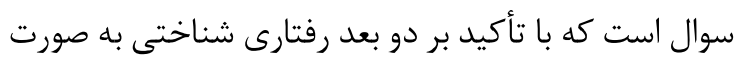


درمانهاى روانشناختى و آموزشى از زمان تشخيص

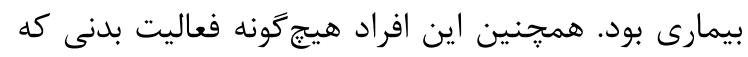
جزو ورزشها محسوب شود (مانند: بيادروى طولانى،

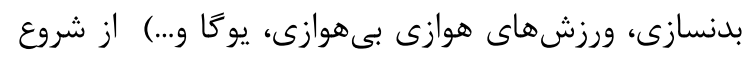

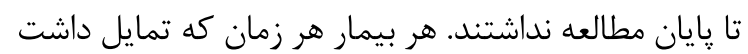
مى توانست آزادانه مطالعه را ترى كند.

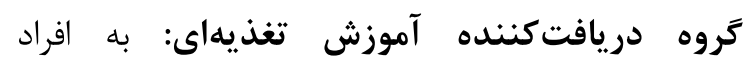

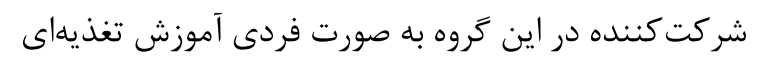
موثر بر كاهش اضطراب و افسردىى توسط كارشناس تغذيه

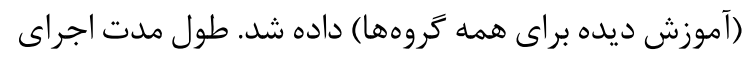

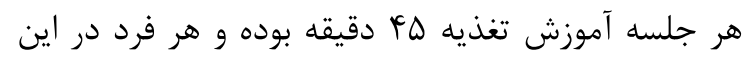

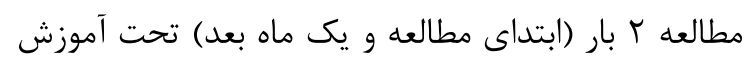
تغذيه قرار كرفت.

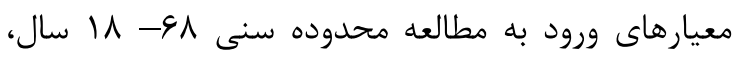

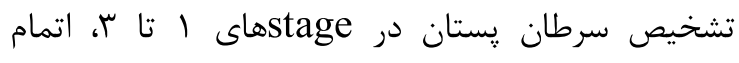

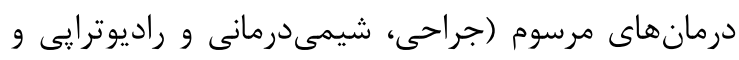

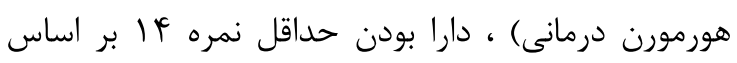

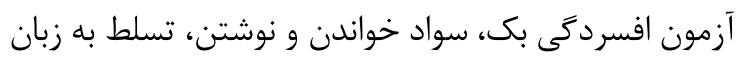

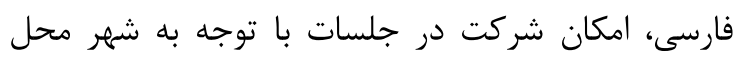

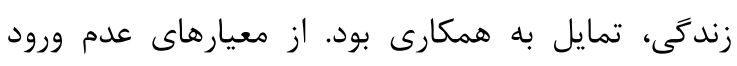

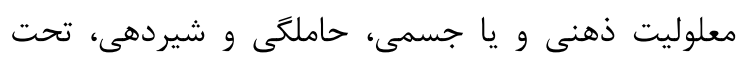

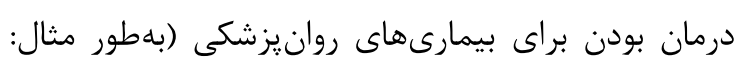

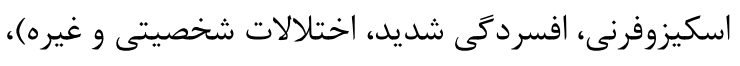

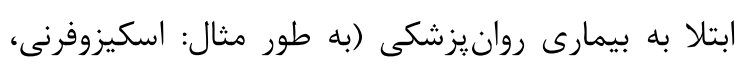
افسردىى شديد، اختلالات شخصيتى و غيره) در صورت تاييد توسط متخصص مربوط، سابقه سوءمصرف مواد،

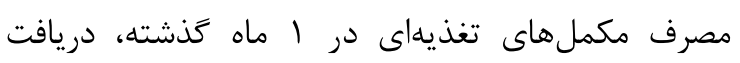

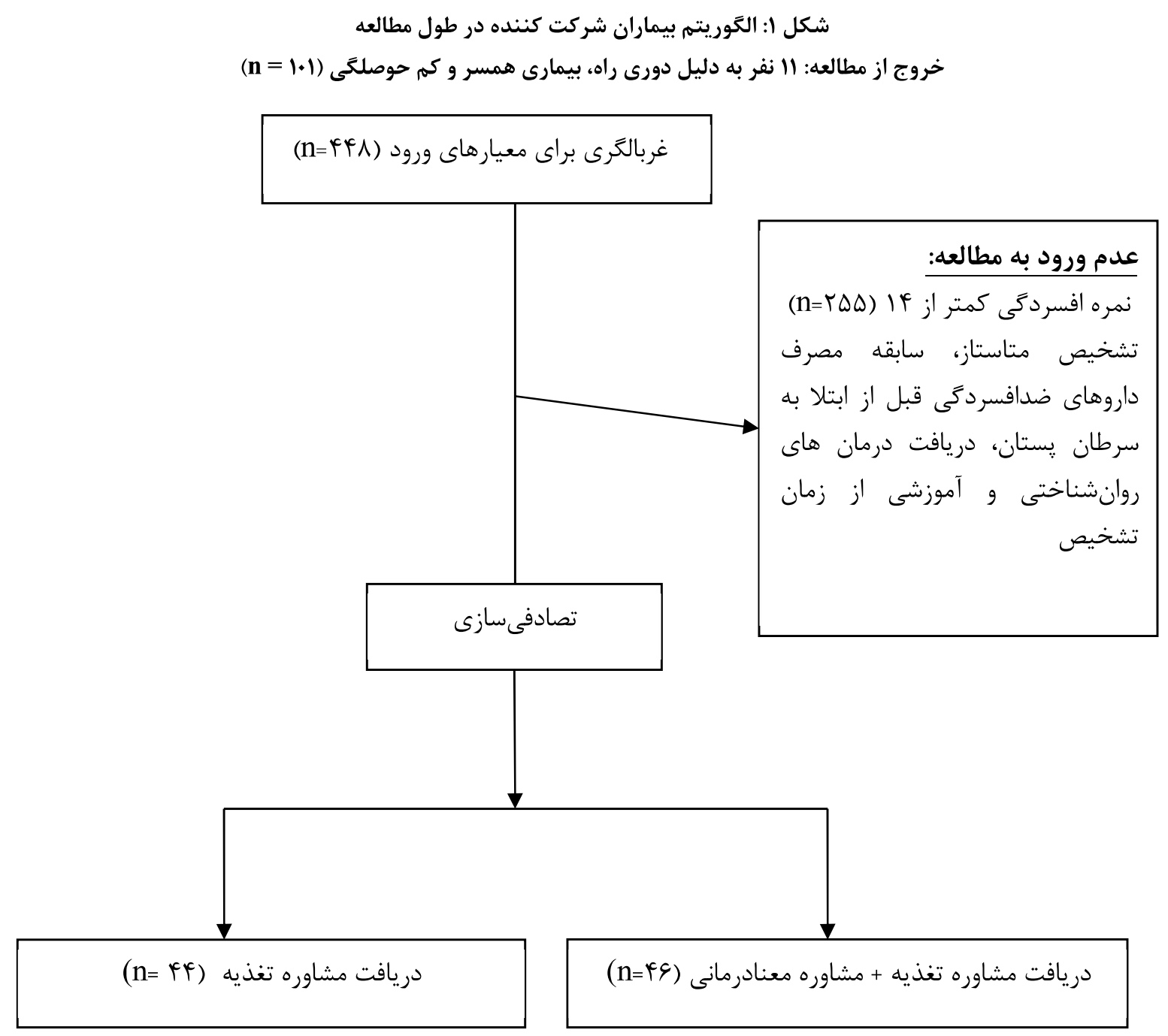


آموزش تغذيه •^.٪ در مرحله يك و دو بيمارى 11\% در

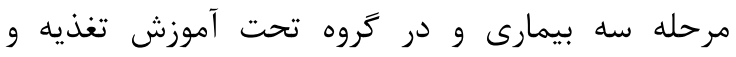

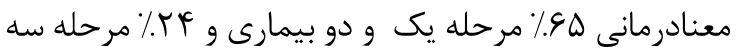

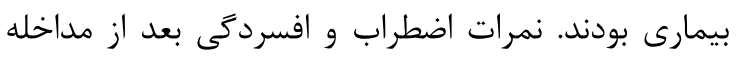

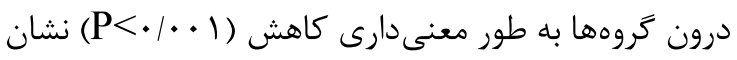

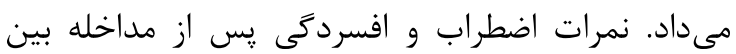

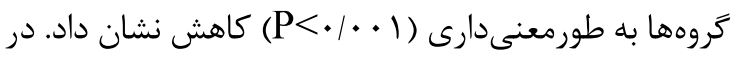

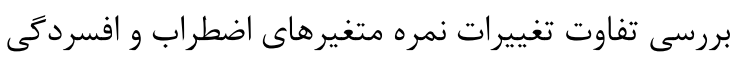

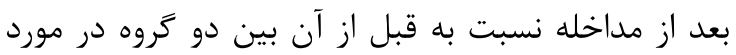

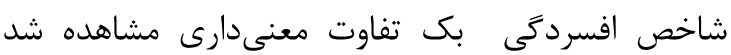
. $(\mathrm{P}<\cdot / \cdot \cdot 1)$

درخصوص توصيف اطلاعات جمعيت شناختى، ميانگين سنى شركتكنند

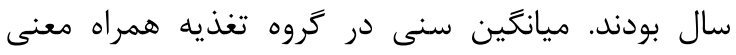

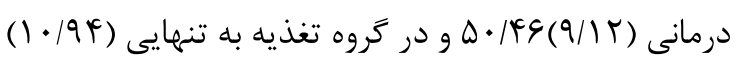
FN/TD بود كه بين دو تروه تفاوت معنى دارى وجود نداشت r

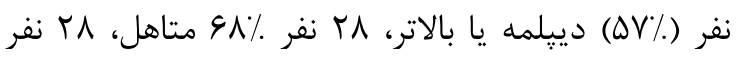

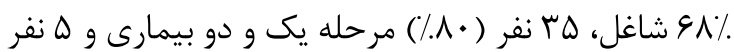

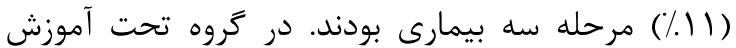

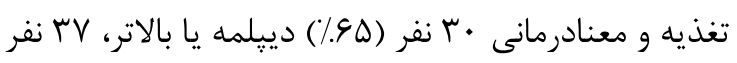

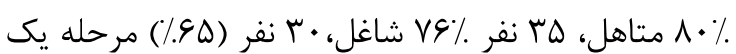

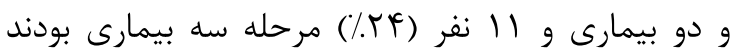
(جدول شماره ()).

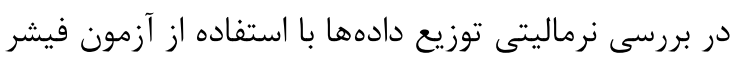
دقيق (Fisher's Exact Test) قبل از مداخله، مشاهده شد كه متغير افسردى توزيع نرمال داشت درحالى كه توزيع متغيرهاى اضطراب و رفتار خوردن نرمال نبود. تغييرات

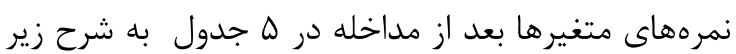

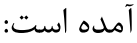
تغييرات نمره اضطراب و افسردكى بعد از مداخله نسبت به قبل از آن در هر يك از تروهها:

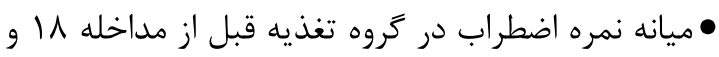
بعد از آن أ أبوده كه اختلاف معنى دارى درون كروهى مشاهده شد (1 (P> P). ميانه نمره اضطراب در كروه

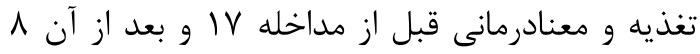
بوده كه با آزمون آمارى ويلكاكسون اختلاف آنداف معنى مدار درون گروهى مشاهده شد (1 . •/•>).
در انتهاى هر جلسه آموزش تغذيه (ابتداى مطالعه و 1 ماه بعد)، يمفلت آموزشى (با محتواى رزيمهاى غذايى مرتبط با تهائ

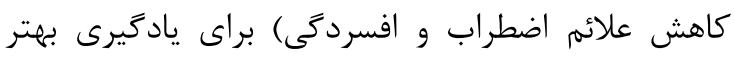

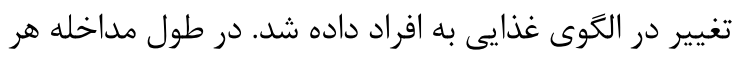

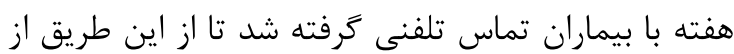
روند اجرايى مداخلهى آموزشى اطمينان لازم حاصل كردد.

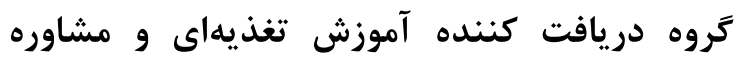

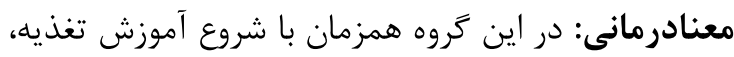
مشاوره معنادرمانى هم به مدت هشت جلسه صورت كرفت

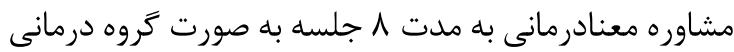
هرهفته يك جلسه انجام شد. در اين ^ جلسه با استفاده از دغدغههاى وجودى و مفاهيم اصلى معنادرمانى مثل آزادى، ئل مسئوليت و وييدا كردن معناى در رنجها و استفاده از ونائ تكنيكهاى قصد متناقض، اصلاح نكرش و بازتابزدايى، دئ

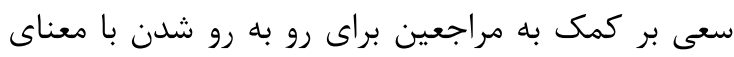

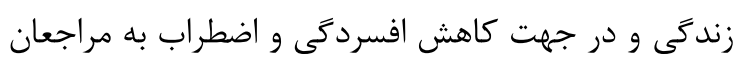

روش تجزيه و تحليل: براى آناليز دادهها از آمار توصيفى

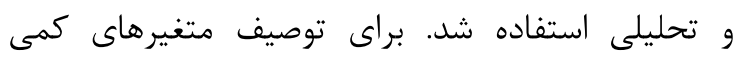

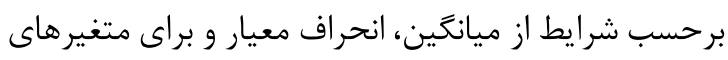
كيفى از كزارش فراوانى (درصد) استفاده شد. براى مقايسه

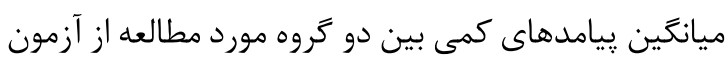

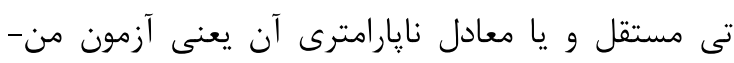

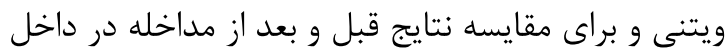

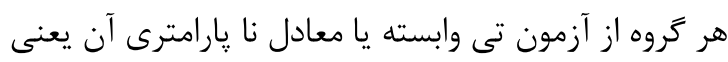
آزمون ويل كاكسون استفاده شد. براى مقايسه فاكتورهاى آنى

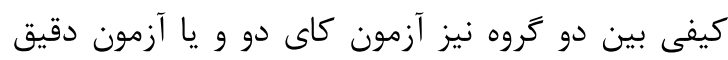

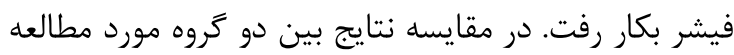
در صورت نياز به كنترل بر متغيرهاى پايه (baseline) برحسب نوع متغير، از مدل هاى ركرسيونى مناسب استفاده

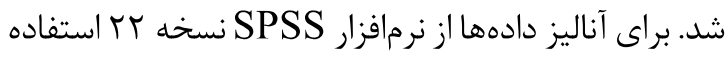

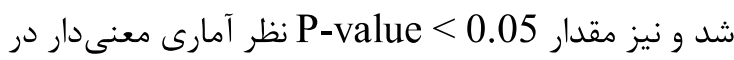
نظر كرفته شد.

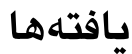

بطور كلى متوسط سن شركت كنند كان سال و٪ بود. از نظر

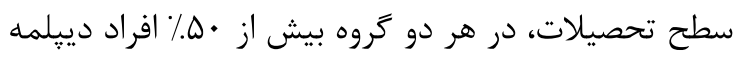

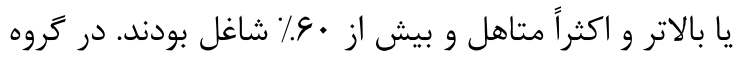




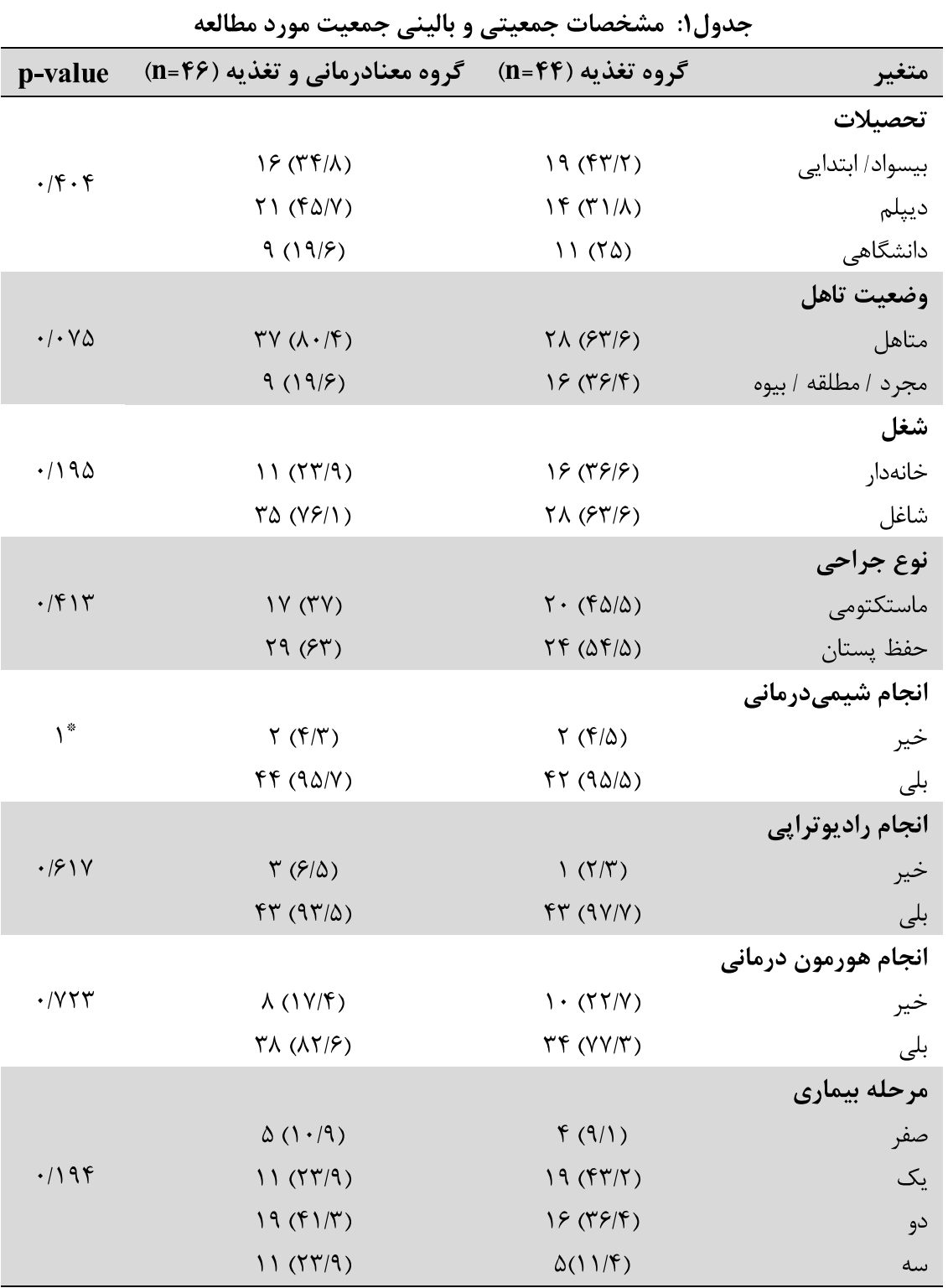

جدول r: آزمون فيشر دقيق" دو كروه تحت مطالعه

\begin{tabular}{|c|c|c|c|}
\hline p-value & 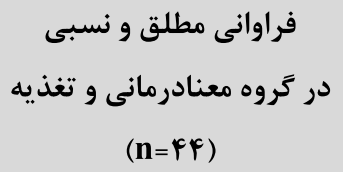 & 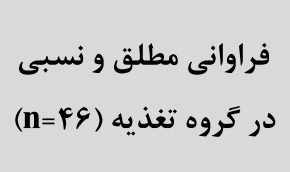 & متغير \\
\hline & ميانغين (انحراف معيار) & ميانگين (انحراف معيار) & \\
\hline$\cdot / \pi \cdot 1$ & $\Delta \cdot / 4 \varphi(q / / r)$ & FN/TA $(1 \cdot / 9 F)$ & سن بيمار \\
\hline$\cdot / 4 q$ & 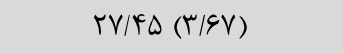 & $r N / \cdot G(4 / 99)$ & شاخص توده بدنى \\
\hline$\cdot 10 \cdot 0$ & $T Y / Q V(T \backslash / T S)$ & $r \Delta / V \Psi(\mid \Lambda / \varepsilon)$ & مدت زمان از تشخيص سرطان (ماه) \\
\hline . MVR & $T V / F \Delta(T / \mathcal{G V})$ & $r \Delta / T F(I V / \Delta \Delta)$ & مدت زمان از تكميل درمان (ماه) \\
\hline$\cdot / r \Delta q$ & $r r / f l(V / r q)$ & $r I / V \cdot(\varepsilon / V)$ & نمره افسردَى \\
\hline$\cdot / V \wedge \vee$ & $\mid N / V \wedge(1 \cdot \mid 9 \cdot)$ & 19/rT (V/A9) & نمره اضطراب \\
\hline
\end{tabular}


اضطراب: با آزمون بين تروهى GEE (آزمون براورديابى

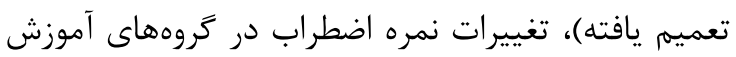

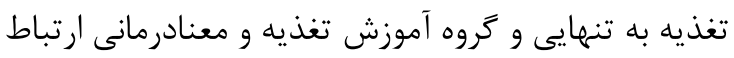

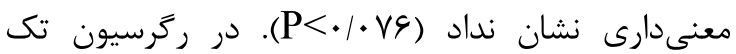

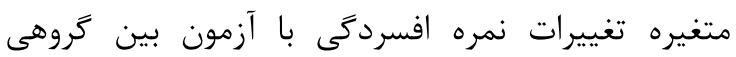

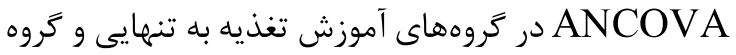

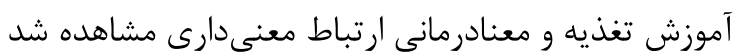
(جدول) (P<• (P)
ميانگين نمره افسردگى در گروه تغذيه قبل از مداخله الب و

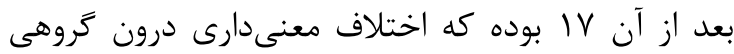

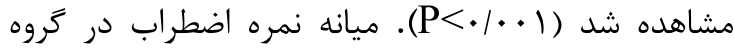

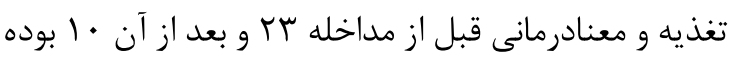

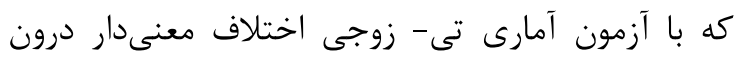

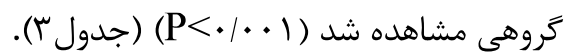

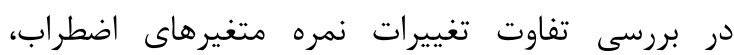

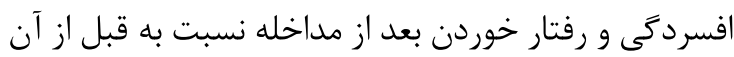
بين دو گروه يافته زير بهدست آمدار خدرن بعد آمداخدا

جدول ץ: تغييرات نمره اضطراب و افسردگى بعد از مداخله نسبت به قبل از آن در هر يك از گروهها

\begin{tabular}{|c|c|c|c|c|c|}
\hline $\mathbf{z}$ & درصد تغييرات & بعد از مداخله & قبل از مداخله & كروههاى مطالعه & متغير \\
\hline$-\Delta / \Delta 9$ & $r \cdot(1 / / 11)$ & If $(q / V \Delta)$ & $11(9)$ & تغذيه & \\
\hline$-\Delta / 91$ & $\Delta \cdot(T Y / \Delta F)$ & $\Lambda(1 \cdot / r \Delta)$ & $I V(I F / T \Delta)$ & تغذيه + معنادرمانى & ارتباط داخل گروهى (ويلكاكسون) ميانه (دامنه بين جاركى) \\
\hline$\Lambda / r q \Delta$ & IN/AV (IT/GQ) & $I V / V \cdot(V / \cdot r)$ & $r I / V \cdot(\varepsilon / 9 V)$ & تغذيه & . \\
\hline IF/AIT & $\Delta \Delta / F V(Y \backslash / V T)$ & $1 \cdot / V G(\varepsilon / 1 V)$ & $r r / f l(V / r q)$ & معنادرمانى + & ارتباط داخل تروهى تى زوجى) \\
\hline
\end{tabular}

$$
\begin{aligned}
& \mathrm{p}<\cdot 1 \cdot+1 \text { * } \\
& \mathrm{p}<\cdot 1 \cdot \cdots 1 \text { *** }
\end{aligned}
$$

\begin{tabular}{|c|c|c|}
\hline 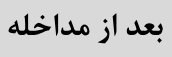 & 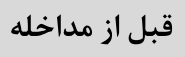 & تروههاى مطالعه \\
\hline If (9/VD & $11(9)$ & 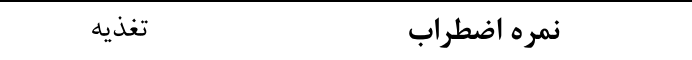 \\
\hline$\Lambda(1 \cdot / r \Delta)$ & $I V(I F / Y \Delta)$ & ميانه (دامنه بين جاركى) \\
\hline \multirow[t]{2}{*}{$-r / V \Delta r$} & $-\cdot / \Delta \wedge r$ & $\mathbf{Z}$ \\
\hline & & *:ارتباط بين كروهى اضطراب در هر مقطع از اندازهيرى \\
\hline$I V / R \cdot(V / \cdot r)$ & $r I / V \cdot(9 / 9 V)$ & نمره افسردَى \\
\hline $1 \cdot / V \varepsilon(8 / 1 V)$ & $r r / 4 \backslash(V / r q)$ & ميانگين (انحراف معيار) \\
\hline \multirow[t]{2}{*}{$4 / 919$} & $-1 / 1 \% \varphi$ & $\mathbf{t}$ \\
\hline & & ***ارتباط بين كروهى افسردىى در هر مقطع از اندازهيرى \\
\hline
\end{tabular}

جدول \&: تفاوت توزيع اضطراب بين دو تروه قبل و بعد از مداخله

p pann-Whitney U Test*

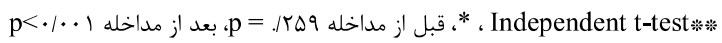


جدوله: تغييرات نمره اضطراب و افسردَى بين و درون كروهها قبل و بعد مداخله

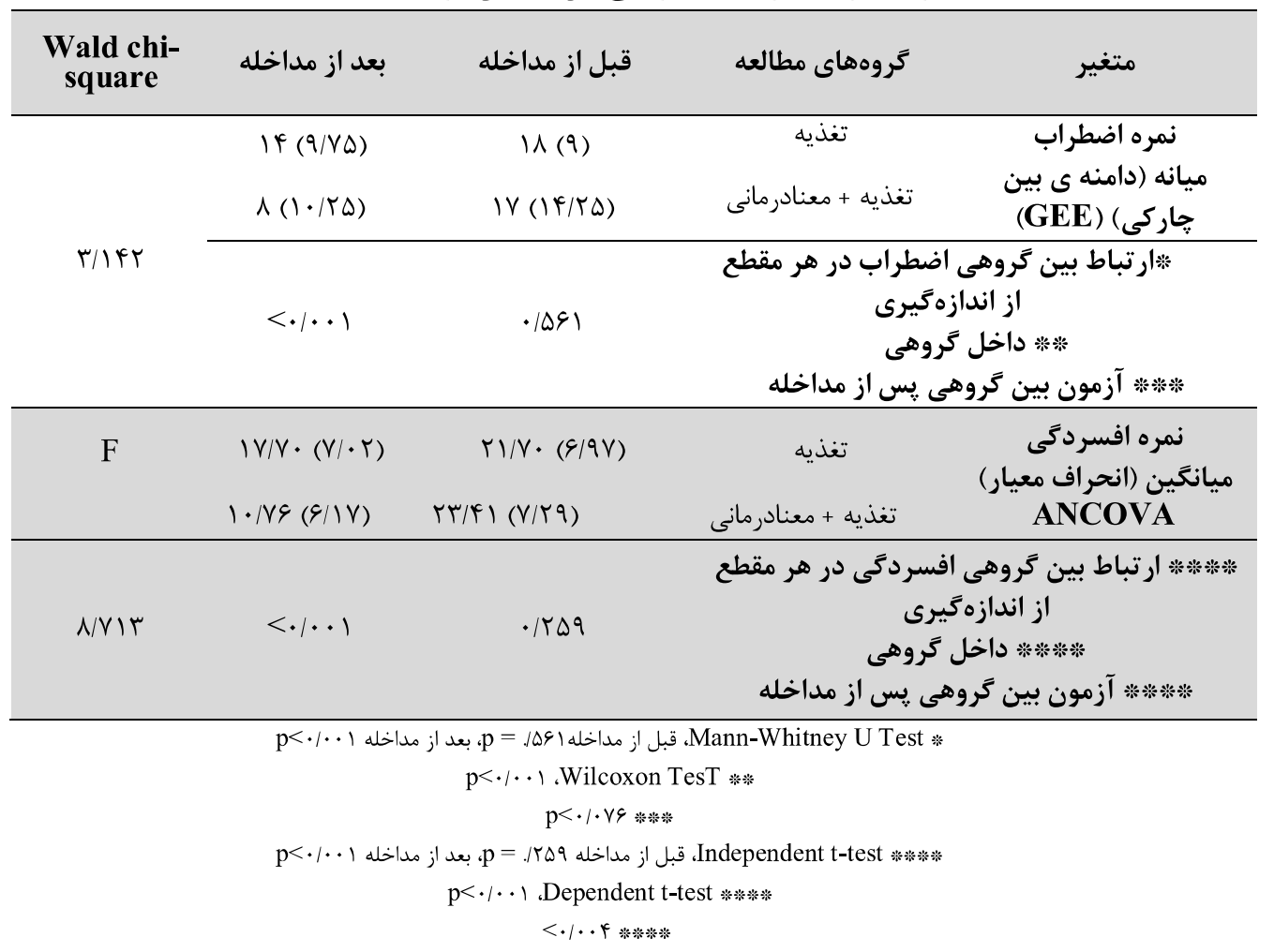

و زندكى دجار ترديد هستند. در بسيارى از موارد اين

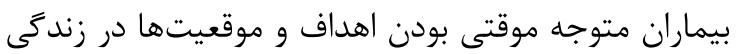

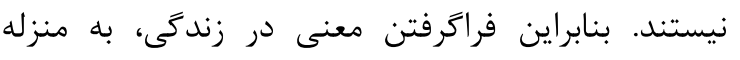

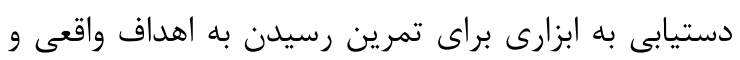

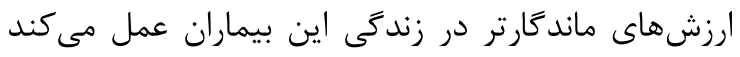

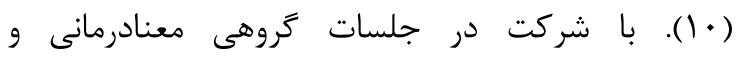

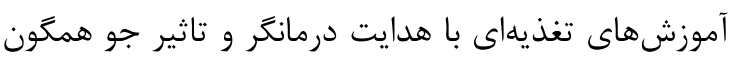

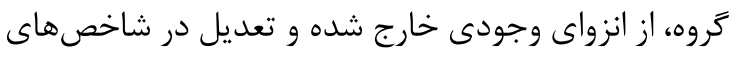
سلامت روان و عادات تغذيهاى افراد ايجاد مى كرددد. اين

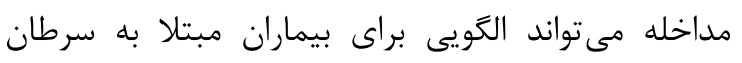

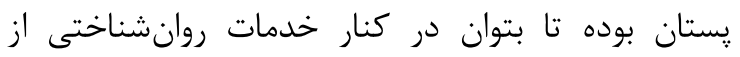

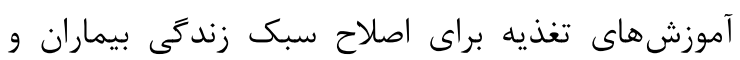
افزايش اميد استفاده كرد.

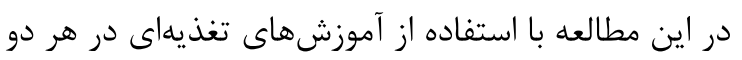
كروه كه اضطراب و افسردگى معنادارى داشتند، نتايج مشابه ساير مطالعات بود. مطالعات نشان مى دهد عادات تغذيهاي

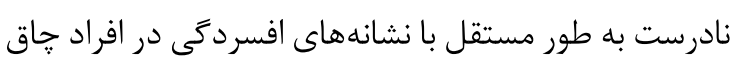

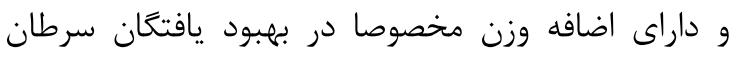

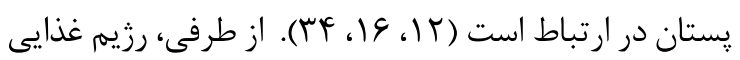

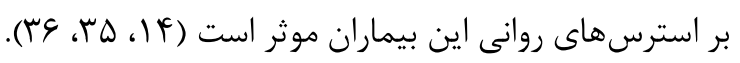
مطالعات نشان مىدهد ممكن است افرادى با خلق منفى،
بحث اين مطالعه نشان مى دهد اضطراب و افسردىى در بيماران

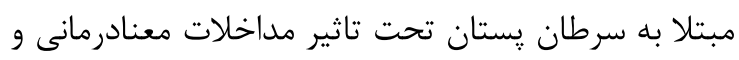

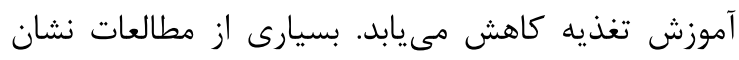

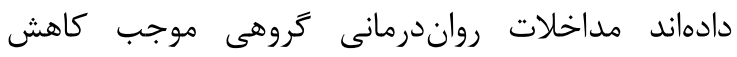

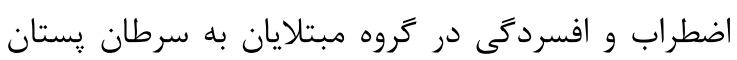

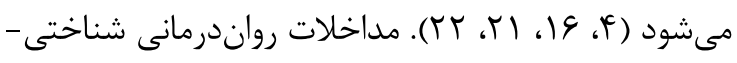

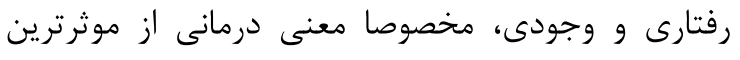

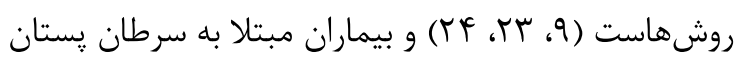

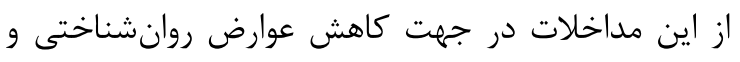

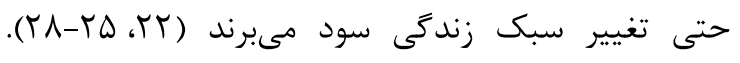

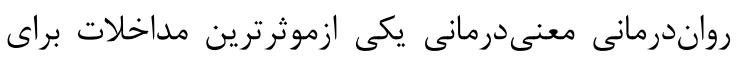

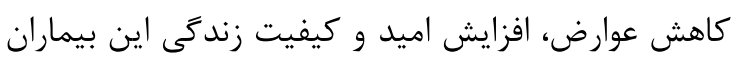

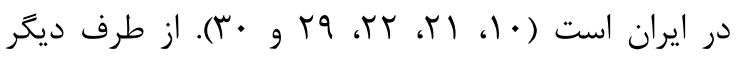

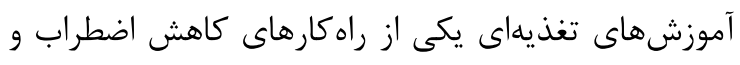

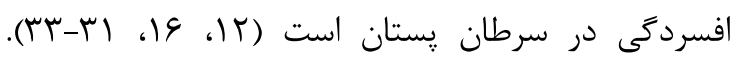

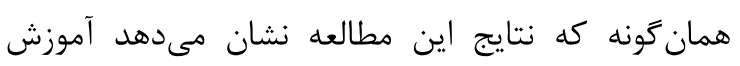

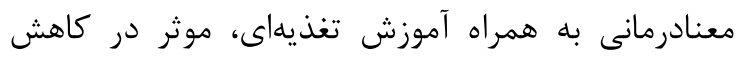

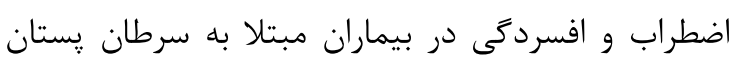

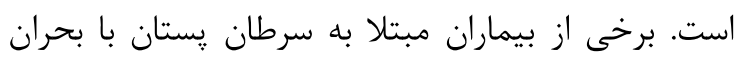

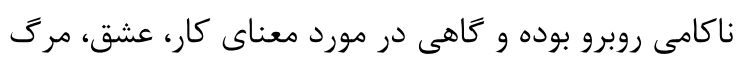


تاكنون انجام نشده است) به عنوان دو بازوى دخيل در تغيير

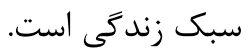
بيشنهادها: بنابر نتايج اين مطالعه و مطالعات مشابه و نيز

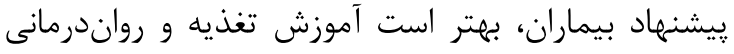

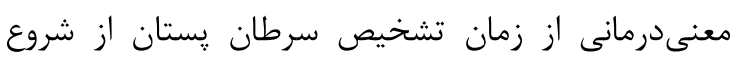

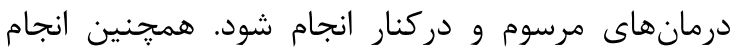

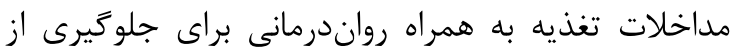
عوارض در انواع سرطان ها توصيه مىشود. براى ارايه بهترين

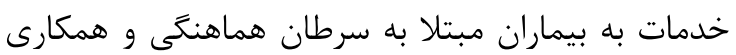
بيشتر سيستمهاى يزشكى، روانشناسى و مشاوران تغذيه

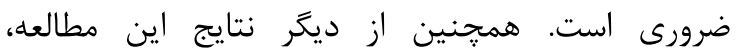
بررسى هايى با محوريت رواندرمانى معنى درمانى و مشاوره تغذيه و مداخلات تغذيهاى خاص مبتلايان به سرطان يستان و نيز بررسى وضعيت روان در شاغلين مبتلا به سرطان يستان توصيه مىشود.

\section{نتيجهكيرى}

مطالعه بر بيماران افسرده بسيار زمان كير است. زيرا بعضا از مشاركت در جلسات رواندرمانى امتناع مى كنند. بنابراين بهتر است طراحى اين گونه مطالعات با همكارى بيشتر كليه

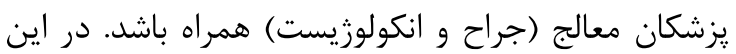
مطالعه بيش از •ه.٪ بيماران داراى تحصيلات متوسط به به

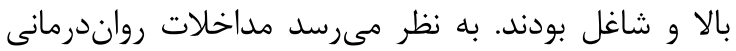

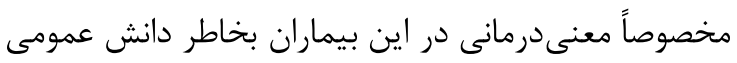

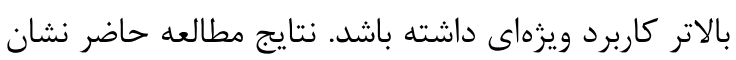

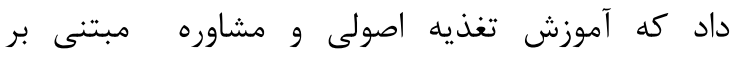

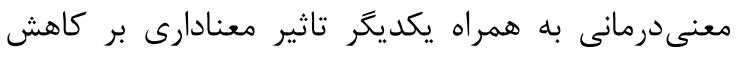

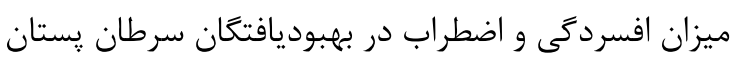
مبتلا به افسردىى در مقايسه با كروه كنترل (مشاوره تغذيه به تنهايى) داشت. استفاده از مداخلات روان درمانى از داز ابتداى درمان تا زمان فراغت از بيمارى، نه تنها موجب ايجات إناد

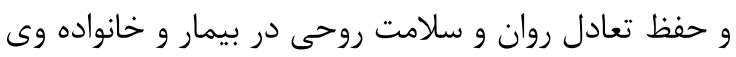

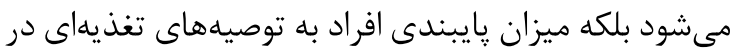
جهت اصلاح سبك زندگى را افزايش مىدهد.

\section{تشكر و قدردانى}

بدينوسيله از تمامى بيماران كه با صبورى نهايت همكارى

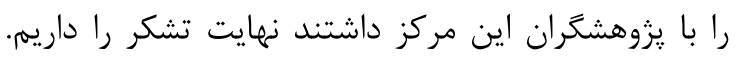

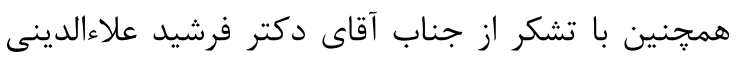

اضطراب و عادات و سبك زندگى نامناسب با درمانهاى با ״ايه شناختى رفتارى و وجودى اصلاح مىشوند (rآ). تبين

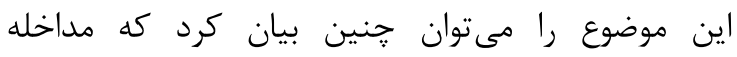

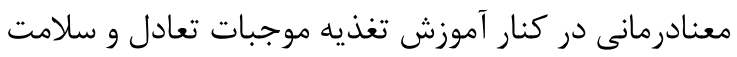

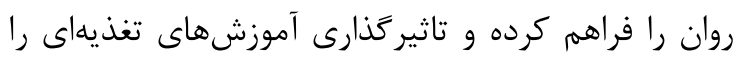

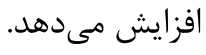
در مقايسه دو روش معنى درمانى به همراه آموزش تغذيه و

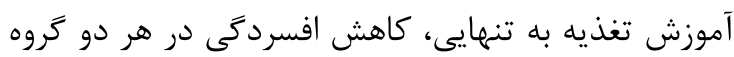
به طور معنى دارى مشاهده شد كه متناسب با نتايج ديخر

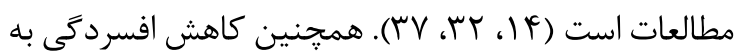

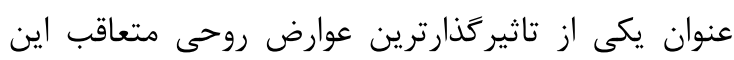

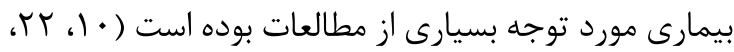

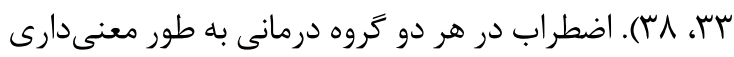

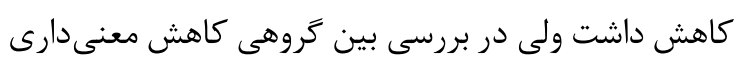

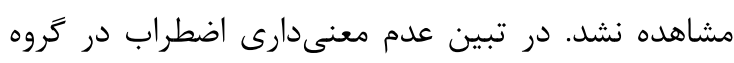

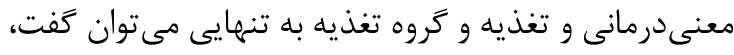

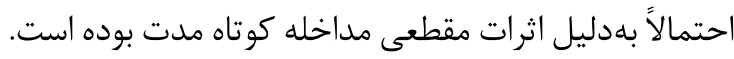

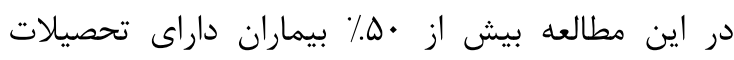

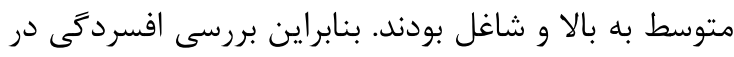

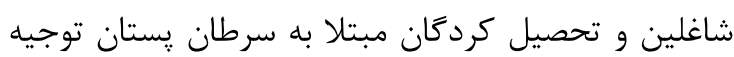
منطقى دارد. در اين مطالعه با توجه به معيار ورود (نمره متوسط

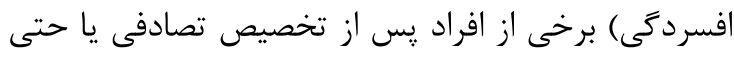

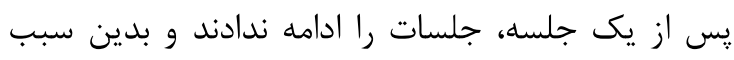

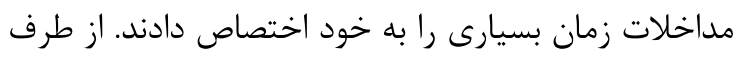

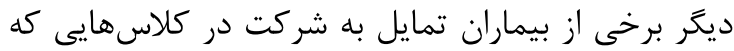

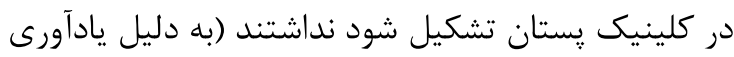
خاطرات جراحى و شيمىدرمانى). برخى از بيماران تقاضاى ندئي

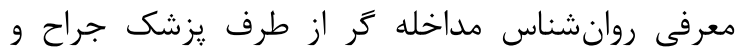
انكولوزيست خود داشتند. از نقاط ضعف مطالعه، تك مركزى بودن و اجراى مطالعه دالهني

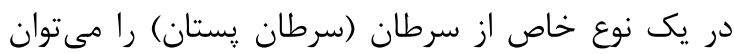

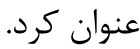
نقطه قوت، در مقايسه با مطالعات مشابه، حجم نمونه اين

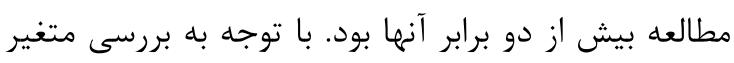

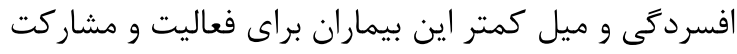

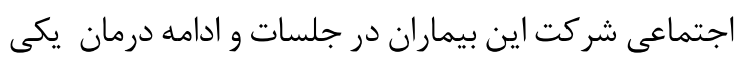

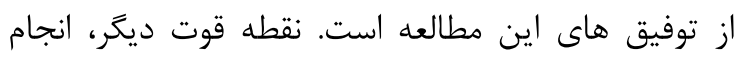

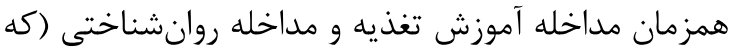




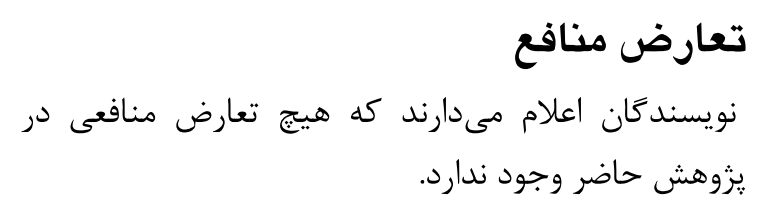

\section{References}

1. Globocan IFJ, Bray F, Pisani P, Parkin D. Cancer incidence, mortality and prevalence worldwide. 2000 .IARCPress GLOBOCAN.

2. Khosravi A, et al. Mortality profile in Iran (29 provinces) over the years 2006 to 2010 . Tehran, Ministry of Health and Medical Education. 2013; 3-21.

3. Hashemi S-M, et al. The prevalence of depression, anxiety, and stress in patients with breast cancer in Southeast Iran in 2019: a crosssectional study. Oncology in Clinical Practice. 2020; 16(3): 104-8.

4. Cvetković J, Nenadović M. Depression in breast cancer patients. Psychiatry research. 2016; 240:343-7.

5. Bower JE, Ganz PA, Irwin MR, Kwan L, Breen $\mathrm{EC}$, Cole SW. Inflammation and behavioral symptoms after breast cancer treatment: do fatigue, depression, and sleep disturbance share a common underlying mechanism? Journal of clinical oncology. 2011; 29(26):3517.

6.Lueboonthavatchai P. Prevalence and Psychological Factors of anxiety and depression in Breast Cancer Patients. Medical association Thailand Journal Chulalongkorn University, Thailand. 2007; 12(2):52-6.

7. Koochaksaraee F, Mostafavi G. [Anxiety and Depression Disorders in Women with Breast and Genital]. Cancer Journal of Nursing and Midwifery1385; 34: 1-28.

8. Corey G. Theory and practice of group counseling: Nelson Education; 2011.

9. Frankel V. Man's search for meaning Boston: Beacon; 2006.

10.Bolhari J, Naziryy Gh, zamaniyan S. The effectiveness of spiritual group therapy approach on reducing depression, Anxiety and stress in women with breast cancer. Journal of Women and Society. 2012; 3(9): 87-117.

11.Grafami H, Shafieabadi A, Sanaee B. [The effectiveness of group semantics on reducing the symptoms of psychological problems in women with breast cancer]. Journal of Thought and Behavior. 1388; 4(14): 35-42.

$$
\begin{aligned}
& \text { إيدميولوزيست محترم كه در بخشى از آناليز اين يزوهش }
\end{aligned}
$$

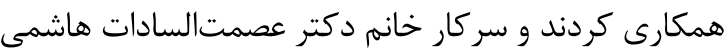

$$
\begin{aligned}
& \text { مدير محترم كلينيك تخصصى بيمارىهاى يستان كه در } \\
& \text { انجام اين يروزه ما را يارى نمودند. }
\end{aligned}
$$

12. Yeter K, Rock CL, Pakiz B, Bardwell WA, Nichols JF, Wilfley DE. Depressive symptoms, eating psychopathology, and physical activity in obese breast cancer survivors. PsychoOncology: Journal of the Psychological, Social and Behavioral Dimensions of Cancer. 2006; 15(6): 453-62.

13. Yu Y, et al. Research progress on the relationship between dietary nutrition, lifestyle and depression. Zhonghua liu xing bing xue za zhi. 2019; 40(4): 481-7.

14. Kaner G, Soylu M, Yüksel N, Inanç N, Ongan D, Başmısırlı E. Evaluation of nutritional status of patients with depression. BioMed research international. 2015; 8(29):82-8.

15.Wang JB, Pierce JP, Ayala GX, CadmusBertram LA, Flatt SW, Madanat $\mathrm{H}$, et al. Baseline depressive symptoms, completion of study assessments, and behavior change in a long-term dietary intervention among breast cancer survivors. Annals of Behavioral Medicine. 2015; 49(6):819-27.

16.Appelhans BM, Whited MC, Schneider KL, Ma Y, Oleski JL, Merriam PA, et al. Depression severity, diet quality, and physical activity in women with obesity and depression. Journal of the Academy of Nutrition and Dietetics. 2012; 112(5): 693-8.

17.Beck AT, Steer RA, Carbin MG. Psychometric properties of the Beck DepressionInventory: Twenty-five years of evaluation. Clin Psychol Rev. 1988; 8(1):77-100.

18.Dabson KM, Mohammad KP. Psychometric characteristics of Beck depression inventory-II in patients with major depressive disorder. Rehabilitation. 2007; 8(29): 82-8.

19. Beck AT, et al. An inventory for measuring clinical anxiety: psychometric properties. Journal of consulting and clinical psychology. 1988; 56(6):893.

20.Kaviani HM, Mousavi A. [Psychometric properties of the Persian version of Beck Anxiety Inventory (BAI)]. Tehran University Medical Journal TUMS Publications. 2008; 66(2):136-40. 
21.Hamid N, Talebian L, Mehrabizadeh Honarmand M, Yavari A. [The effectiveness of meaning therapy on depression, anxiety and quality of life in cancer patients]. Journal of Psychological Achievements. 2011; 18 (2): 199-224.

22.Thune-Boyle IC, Stygall JA, Keshtgar MR, Newman SP. Do religious/spiritual coping strategies affect illness adjustment in patients with cancer? A systematic review of the literature. Social science \& medicine. 2006; 63(1):151-64.

23.Yalom ID. Existential psychotherapy: 2020. Hachette UK.

24.Breitbart W, Rosenfeld B, Pessin H, Applebaum A, Kulikowski J, Lichtenthal WG. Meaning- centered group psychotherapy: an effective intervention for improving psychological well-being in patients with advanced cancer. Journal of Clinical Oncology. 2015; 33(7):749.

25.Rogols JT, Wolfe PE. Existential Considerations and the Role of Second Wave Positive Psychology in Counseling Clients with Cancer. USA: The Ohio State University; 2018.

26.Fauver $\mathrm{R}$. The healing wisdom within: A preliminary experimental trial of PsychoSpiritual Integrative Therapy for people with cancer. Palo Alto California: Institute of Transpersonal Psychology; 2011.

27. Rosequist L. The experience of surrender: For women with non-metastatic breast cancer undergoing a Psychospiritual Integration and Transformation (PSIT) intervention. 2009. Palo Alto ,California,Institute of Transpersonal Psychology.

28.Garlick MA. Physical, psychological, spiritual, and posttraumatic growth experiences of women with breast cancer participating in a psychospiritual integration and transformation course. Parkway:.Institute of Transpersonal Psychology; 2009.

29. Hosseinian S, Qasemzadeh S, Taziki T. [The effectiveness of group meaning therapy on mental health and quality of life in women with breast cancer]. Cultural education of women and family.1392; 8(25): 8-31.

30. Mohabbat-Bahar S, Golzari M, Moradi-Joo M, Akbari ME. [Efficacy of group logotherapy on decreasing anxiety in women with breast cancer]. Iranian journal of cancer prevention. 2014; 7(3): 165.

31. Sánchez-Villegas A, Delgado-Rodríguez M, Alonso A, Schlatter J, Lahortiga F, Majem LS, et al. Association of the Mediterranean dietary pattern with the incidence of depression: the Seguimiento Universidad de Navarra/University of Navarra follow-up (SUN) cohort. Archives of general psychiatry. 2009; 66(10):1090-8.

32. Thomas M. Existential interventions in eating disorders: University of Nottingham; 2001.

33. Alimohammadi M, Sharifi-Daramadi P, Noohi S. Effectiveness of Group Logo-Therapy Program on Existential Anxiety among Patients with Metabolic Syndrome. International Journal of Advanced Biological and Biomedical Research (IJABBR). 2020; 8(3): 268-82.

34. Lima MTM, Maruyama TC, Custódio IDD, da Costa Marinho E, Ferreira IB, Crispim CA, et al. The impact of a higher eating frequency on the diet quality and nutritional status of women with breast cancer undergoing chemotherapy. British Journal of Nutrition. 2020; 123(4):4108.

35. Gangwisch JE, Hale L, Garcia L, Malaspina D, Opler MG, Payne ME, et al. High glycemic index diet as a risk factor for depression: analyses from the Women's Health Initiative. The American journal of clinical nutrition. 2015; 102(2):454-63.

36. Maunsell E, Drolet M, Brisson J, Robert J, Deschênes L. Dietary change after breast cancer: extent, predictors, and relation with psychological distress. Journal of Clinical Oncology. 2002; 20(4):1017-25.

37. Mamplekou E, Bountziouka V, Psaltopoulou T, Zeimbekis A, Tsakoundakis N, Papaerakleous $\mathrm{N}$, et al. Urban environment, physical inactivity and unhealthy dietary habits correlate to depression among elderly living in eastern Mediterranean islands: the MEDIS (MEDiterranean ISlands Elderly) study. The journal of nutrition, health \& aging. 2010; 14(6):449-55.

38. Yeganeh T. [The role of religious orientation in determining hope and psychological wellbeing of women diagnosed with breast cancer]. 2014; 6(3):47-56. 